\author{
Marquette University \\ e-Publications@Marquette
}

College of Nursing Faculty Research and

Publications

Nursing, College of

7-2016

\title{
Parents' Perspectives on Shared Decision Making for Children With Solid Organ Transplants
}

Stacee M. Lerret

Medical College of Wisconsin

Kristin Haglund

Marquette University, kristin.haglund@marquette.edu

Norah L. Johnson

Marquette University, norah.johnson@marquette.edu

Follow this and additional works at: https://epublications.marquette.edu/nursing_fac

Part of the Nursing Commons

\section{Recommended Citation}

Lerret, Stacee M.; Haglund, Kristin; and Johnson, Norah L., "Parents' Perspectives on Shared Decision Making for Children With Solid Organ Transplants" (2016). College of Nursing Faculty Research and Publications. 434.

https://epublications.marquette.edu/nursing_fac/434 
Marquette University

\section{e-Publications@Marquette}

\section{Nursing Faculty Research and Publications/ College of Nursing}

This paper is NOT THE PUBLI SHED VERSI ON; but the author's final, peerreviewed manuscript. The published version may be accessed by following the link in the citation below.

Journal of Pediatric Health Care, Vol 30, No. 4 (J uly/August 2016): 374-380. DOI. This article is (c) Elsevier and permission has been granted for this version to appear in ePublications@Marquette. Elsevier does not grant permission for this article to be further copied/distributed or hosted elsewhere without the express permission from Elsevier.

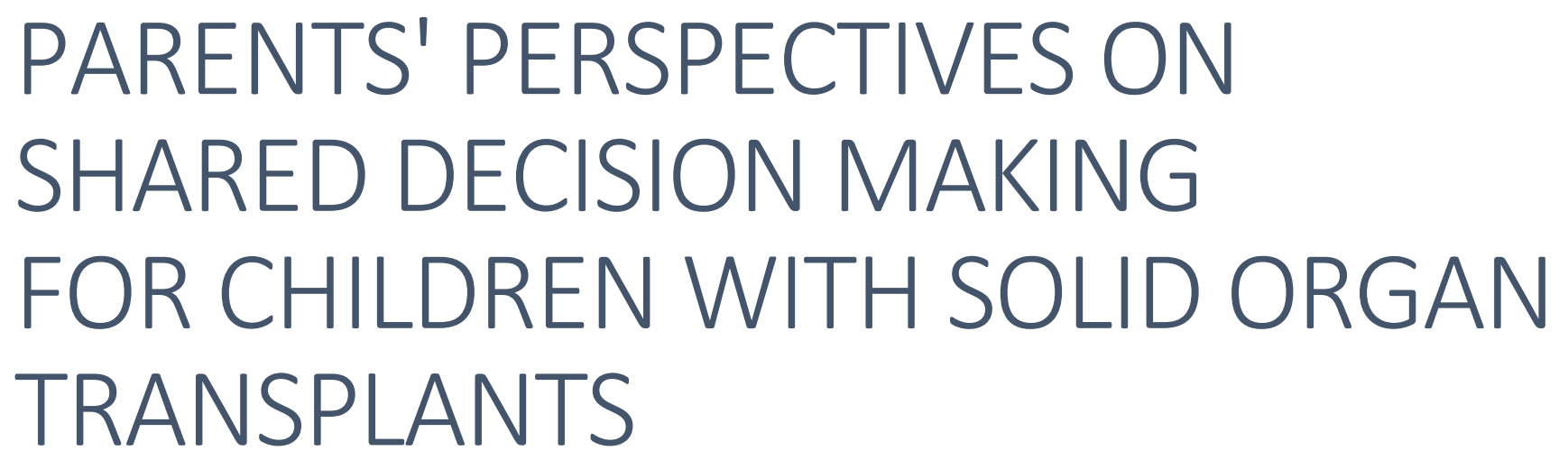

Stacee M. Lerret

Division of Pediatric Gastroenterology and Transplant Surgery, Medical College of Wisconsin, Milwaukee, WI Kristin A. Haglund

College of Nursing, Marquette University, Milwaukee, WI

Norah L. Johnson

College of Nursing, Marquette University, Milwaukee, WI

\section{Abstract \\ Introduction}

The Institute of Medicine prioritizes active family and clinician participation in treatment decisions, known as shared decision making (SDM). In this article we report the decision-making experiences for parents of children who had a solid organ transplant. 


\section{Method}

We performed a prospective longitudinal mixed methods study at five major U.S. children's medical centers. Qualitative interview data were obtained at 3 weeks, 3 months, and 6 months after hospital discharge following the child's transplant.

\section{Results}

Forty-eight parents participated in the study. Three themes were identified: (a) Parents expect to participate in SDM; (b) parents seek information to support their participation in SDM; and (c) attributes of providers' professional practice facilitates SDM. SDM was facilitated when providers were knowledgeable, transparent, approachable, accessible, dependable, and supportive.

\section{Conclusions}

Parents expect to participate in SDM with their transplant team. Health care providers can intentionally use the six key attributes to engage parents in SDM. The results provide a framework to consider enhancing SDM in other chronic illness populations.

\section{Key Words}

Shared decision making, chronic illness, solid organ transplant, qualitative

Pediatric solid organ transplant (SOT) recipients are medically fragile and have complex home management regimens. Parents of transplant recipients typically experience uncertainty during the transplant process (Shellmer, Brosig, \& Wray, 2014). They have reported stress (Aldridge, 2008) and difficulty with coping, managing life at home, and adhering to complex care regimens (Lerret et al., 2015; Lerret \& Weiss, 2011), which may result in posttransplant complications. Collaboration between patients, families, and health care professionals improves health outcomes and decreases rates of readmission and complications in populations of persons with complex chronic conditions (Committee on Hospital Care and Institute for Patient and Family Centered Care, 2012). Engaging patients and families in collaboration is referred to as shared decision making (SDM) in current health care policies, including the Affordable Care Act (Informed Medical Decisions Foundation, $\underline{2015})$.

The Institute of Medicine encourages SDM as a method of fostering improved patient satisfaction with health care (Institute of Medicine [IOM], 2001). SDM has been recognized for years as a process of four components: (a) active participation of both clinicians and families in treatment decisions, (b) exchange of information, (c) discussion of preferences, and (c) joint determination of treatment plans (Charles, Gafni, \& Whelan, 1997). With SDM both the provider and patient are involved in the decision-making process, express treatment preferences, and mutually agree on a treatment plan (Fiks, Localio, Alessandrini, Asch, \& Guevara, 2010), focusing on the aspects of care that matter most to the child and parent (Barr et al., 2014; IOM, 2015). Parents see themselves as the expert for their child and report SDM as a partnership with their provider (Fiks, Hughes, Gafen, Guevara, \& Barg, 2011).

SDM may be an intermediary step to patient activation. Patient activation refers to the skills and confidence that equip patients to become actively engaged in their health care (Hibbard \& Greene, 2013). Patient activation has been shown to contribute to better health outcomes and health care experiences (Hibbard \& Greene, 2013). Intentional use of patient-empowering provider behaviors could lead to improved patient activation and functional health status (Jerofke, Weiss, \& Yakusheva, 2014). 
SDM is a process advocated by professionals and most often studied from the perspectives of professionals. Researchers have measured parents' decision-making behaviors quantitatively, but few qualitative studies have been performed in which parents expressed their perspectives on making health care decisions on behalf of their children (Coyne, O'Mathuna, Gibson, Shields, \& Sheaf, 2013; Kavanaugh, Savage, Kilpatrick, Kimura, \& Hershberger, 2005; Pentz et al., 2012). Further, SDM has not been explored among parents of children facing SOT. The data reported in this article were part of a larger study designed to explore discharge preparation and the effects of that preparation on postdischarge care (Lerret et al., 2015). Parents in this study responded to questions about medical decision making; their responses reflected the components of SDM previously identified in the literature. The purpose of this article is to report the experiences of medical decision making among parents of children who had an SOT. The results have implications for health care providers in acute and primary care settings.

\section{Methods}

\section{Study Setting and Recruitment of Participants}

This prospective, qualitative, longitudinal study was conducted at five major children's medical centers in the United States after Institutional Review Board approval was obtained at each site. Recruitment via convenience sampling took place from July 2010 to January 2012 among parents identified as the primary caregiver of a child who had received a heart, kidney, liver, lung, or multivisceral transplant. The inclusion criteria included being 18 years or older, speaking English, and having access to a telephone to complete the postdischarge telephone interviews. Parents of children who had a previous transplant or a serious co-morbid condition were excluded because these circumstances would have changed the families' discharge preparation, which was the focus of the original study.

Near the time of hospital discharge, the transplant coordinator or research assistant identified eligible parents and explained the study. Fifty-nine eligible parents were invited to participate in the study, and 51 were enrolled on the day of hospital discharge. High retention was achieved during the 6-month time frame of the study, with 48 participants at 3 weeks, 46 participants at 3 months, and 44 participants at 6 months (see the Figure). Data for the study reported in this article were collected via semi-structured telephone interviews completed at 3 weeks, 3 months, and 6 months after hospital discharge by the research assistant and principal investigator (SL). Participants were asked about their perspectives and experiences regarding caring for their children after discharge, participation in medical decision making, and interactions with the transplant team (see Table 1). Parents' responses were audio recorded and transcribed verbatim by one of the researchers. 


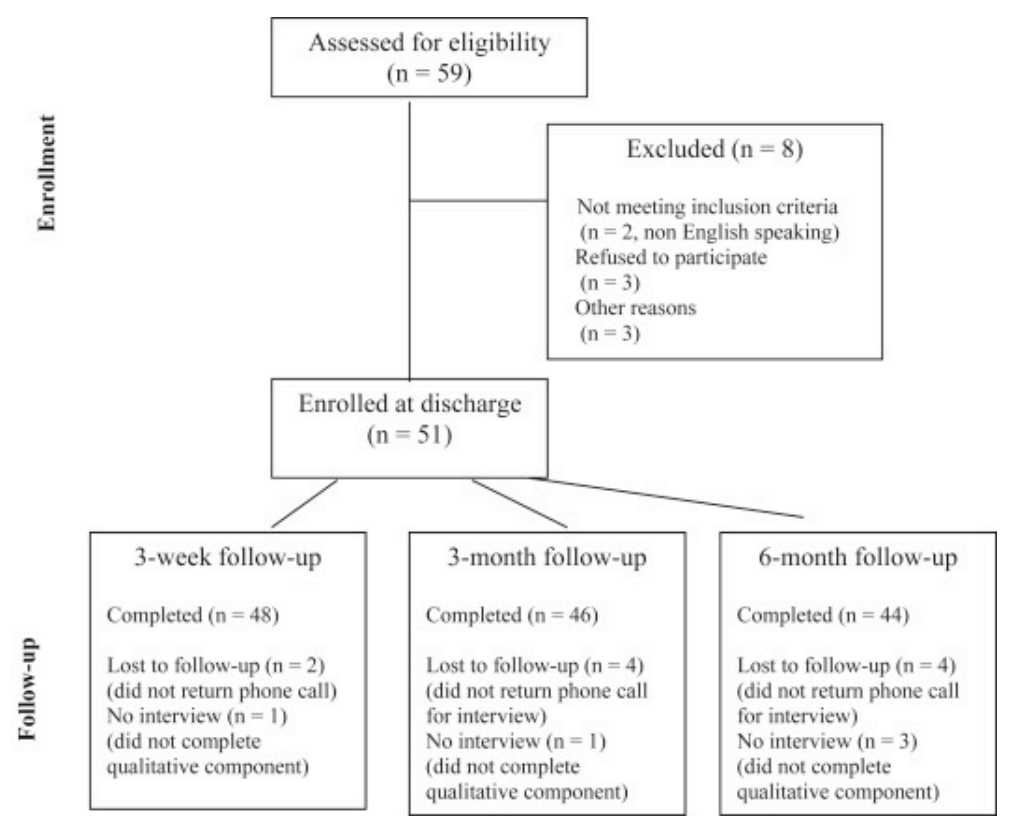

Figure. Participant enrollment attrition summary.

Table 1. Qualitative questions asked at 3 weeks, 3 months, and 6 months after hospital discharge Question No. Question

1 Tell me about the challenges and obstacles in the last ( 3 weeks, 3 months or 6 months) after your child's transplant.

$2 \quad$ How do you participate in medical decision making?

$3 \quad$ How does your transplant team help you manage your child's condition?

$4 \quad$ What should the transplant team continue to do or improve upon to help you manage your child's condition?

Transcriptions were entered into NVivo (QSR International, Melbourne, Australia), a software program for qualitative data analysis. Data were coded by one researcher $(\mathrm{KH})$. The coded data were discussed in multiple research team meetings and codes were revised until consensus was reached regarding the names of the codes and how they were applied to the data. After coding was complete, data were examined within each main and subcode to generate descriptions of participants' experiences and perspectives. The research team discussed the coded data and descriptions to identify themes. Themes were refined until they concisely reflected the participants' points of view regarding participation in decision making and their expectations of their health care providers.

\section{Results}

\section{Characteristics of Participants}

The majority of parents (median age, 34 years; range, 19-55 years) were female ( $n=41 ; 85 \%)$, white $(n=39$; $81 \%)$, and married ( $n=34 ; 71 \%)$. The children (median age, 2.8 years; range, 3 weeks to 17.5 years), received a liver $(n=20 ; 41 \%)$, heart $(n=15 ; 31 \%)$, kidney $(n=8 ; 16 \%)$, multivisceral $(n=5 ; 10 \%)$ or lung $(n=1 ; 2 \%)$ transplant (see Table 2 for additional descriptors). 
Table 2. Demographic and medical characteristics of the study population $(n=48)$

\begin{tabular}{|c|c|}
\hline Characteristic & $N(\%)$ \\
\hline \multicolumn{2}{|l|}{ Organ type } \\
\hline Liver & $20(41)$ \\
\hline Heart & $15(31)$ \\
\hline Kidney & $8(16)$ \\
\hline Multivisceral & $5(10)$ \\
\hline Lung & $1(2)$ \\
\hline \multicolumn{2}{|l|}{ Parent gender } \\
\hline Female & $41(85)$ \\
\hline Male & $7(15)$ \\
\hline \multicolumn{2}{|l|}{ Parent age, years $(n=48)$} \\
\hline Median & 34.0 \\
\hline Range & $19-55$ \\
\hline \multicolumn{2}{|l|}{ Parent race } \\
\hline White & $39(81)$ \\
\hline Black & $7(15)$ \\
\hline Alaskan or American Indian & $2(4)$ \\
\hline \multicolumn{2}{|l|}{ Child race } \\
\hline White & $39(81)$ \\
\hline Black & 9 (19) \\
\hline \multicolumn{2}{|l|}{ Parent marital status } \\
\hline Married & $34(71)$ \\
\hline Single & $11(23)$ \\
\hline Divorced & $1(2)$ \\
\hline Widowed & $1(2)$ \\
\hline Did not answer & $1(2)$ \\
\hline \multicolumn{2}{|l|}{ Child gender } \\
\hline Male & $24(50)$ \\
\hline Female & $24(50)$ \\
\hline \multicolumn{2}{|l|}{ Child age, years } \\
\hline Median & 2.8 years \\
\hline Range & 3 weeks to 17.5 years \\
\hline \multicolumn{2}{|l|}{ Inpatient No. of days } \\
\hline Median & 13.5 \\
\hline Range & $4-90$ \\
\hline \multicolumn{2}{|l|}{ Hospitalization complications } \\
\hline Infection & $7(14)$ \\
\hline Rejection & $4(8)$ \\
\hline
\end{tabular}


Characteristic

No. of medications at time of hospital discharge

Median

Range

Additional medical needs at time of hospital discharge

Wound care

$17(35)$

Enteral or tube feeding

Central line care

Drainage tube
$N(\%)$

10

5-21
$3(6)$

\section{Theme 1: Parents Expect to Participate in Shared Decision Making}

In Table 3 we present the four components of SDM, parents' decision-making behaviors, and illustrative quotations drawn from the 3-week interviews. Of the parents in this study, 31 (65\%) expressed active participation in medical decision making. Of these parents, seven appeared to anticipate that the transplant team might not include them in decision making and expressed their intention to make their point of view known to the transplant team whether or not they perceived it to be welcome. Fewer participants $(n=13 ; 27 \%)$ reported passive involvement in decision making, stating that after the team presented the plan, they sought clarification and then agreed to follow the recommended plan of care. Parents more commonly considered the providers' preferences compared with voicing their preferences for their children's care $(75 \% \mathrm{vs.} 25 \%$, respectively). They also more commonly sought information from the providers than gave information to providers ( $44 \%$ vs. $4 \%$, respectively). Most parents ( $n=34 ; 71 \%$ ) reported agreement with the team on the treatment plan for their children. Of these parents, $40 \%(n=19)$ reported that the decisions were shared between the parents and the team and $31 \%(n=15)$ reported that the team made the treatment decisions and parents went along with what the team decided. No parent used the term "shared decision making." However, the decision-making behaviors identified in the 3-week interviews fit the components of SDM. The interviews performed 3 weeks after discharge included the richest data describing decision making. At 3 and 6 month after discharge, most parents stated that either they were no longer making medical decisions or the nature of the decisions had changed to more routine issues such as use of sunscreen, participation in sports, nutrition, and immunizations.

Table 3. Parents' shared decision-making behaviors

$\begin{array}{ll}\text { Component of Parents' behaviors } & \begin{array}{l}\text { Cases, }, \boldsymbol{N} \\ \text { SDM }\end{array} \\ (\% \text { of } 48)\end{array} \quad$ Illustrative quotations

1. Parent and Active participation $31(65)$ "I fully believe that it's a two-way street; parents need provider involved to educate themselves; the doctors can only do so much in SDM and can only know from what the parents tell them" Passive participation $13(27)$ "We just do whatever the doctors tell us to do at his appointment"

\section{Share information with each other \\ Ask provider for information}

Give provider information
"We ask a lot of questions...we want to really understand what is going on"
"I participate by keeping them informed of what's going on with my child" 


\begin{tabular}{|c|c|c|c|}
\hline $\begin{array}{l}\text { Component of } \\
\text { SDM }\end{array}$ & Parents' behaviors & $\begin{array}{l}\text { Cases, }, \text { a } \\
(\% \text { of } 48)\end{array}$ & Illustrative quotations \\
\hline \multirow[t]{2}{*}{$\begin{array}{l}\text { 3. Express } \\
\text { treatment } \\
\text { preferences }\end{array}$} & $\begin{array}{l}\text { Consider teams' } \\
\text { preferences }\end{array}$ & $36(75)$ & $\begin{array}{l}\text { "The doctors go over what they feel needs to be done } \\
\text { and why"; "We ask questions to understand why they } \\
\text { want to do the things they do" }\end{array}$ \\
\hline & $\begin{array}{l}\text { Express preferences } \\
\text { to team }\end{array}$ & $12(25)$ & $\begin{array}{l}\text { "We always give our opinions and we're not afraid to } \\
\text { ask questions" }\end{array}$ \\
\hline \multirow[t]{2}{*}{$\begin{array}{l}\text { 4. Agree on } \\
\text { treatment plan }\end{array}$} & $\begin{array}{l}\text { Parents and team } \\
\text { make shared } \\
\text { decisions }\end{array}$ & $19(40)$ & $\begin{array}{l}\text { "I'm not making medical decisions, but rather } \\
\text { participating in all of the medical decisions that are } \\
\text { made by the doctor" }\end{array}$ \\
\hline & $\begin{array}{l}\text { Team makes } \\
\text { decisions that parents } \\
\text { agree with }\end{array}$ & $15(31)$ & $\begin{array}{l}\text { "The doctors always let us know what they're doing and } \\
\text { why they're doing it so we usually just go along with } \\
\text { what they say" }\end{array}$ \\
\hline
\end{tabular}

Note. SDM = shared decision making.

${ }^{a}$ Cases is the number of parents who stated engaging in the behavior at the 3-week interview.

\section{Theme 2: Parents Seek Information to Support Their Participation in SDM}

Some parents $(n=20 ; 42 \%)$ reported that they participated in decision making by seeking information. They recognized that they lacked knowledge regarding many aspects of their children's cases. They sought information by reading "...whatever we can get our hands on," doing research on the Internet, and consulting with their primary care pediatricians, their family members, and other families who had experienced a transplant. This information prepared them for discussions with the transplant team. Parents brought lists of questions and concerns to meetings with the team because they viewed the nurses and physicians on the transplant team as their primary sources of information. Additionally, parents expected the teams to satisfy their information needs on an ongoing basis and wanted providers to deliver information in a professional, considerate, and complete manner. The parents did not want providers to judge them or their questions. They expected respect and kindness and did not want responses from providers that made them feel inadequate or unintelligent. The team's willingness to talk with families until they understood the plan engendered trust and satisfaction and facilitated parents' decision to follow the team's recommendations.

\section{Theme 3: Attributes of Providers' Professional Practice Facilitates SDM}

The team approach adopted by the transplant providers facilitated SDM. Parents referenced "the team" when discussing the care providers of their children. Parents felt they were a part of the team that was working together to care for their children. Feelings of being included on the team strengthened their solidarity with the providers and their trust and confidence in decisions made regarding their children. Parents were asked how the transplant team helped them to manage their children's conditions. Their responses were spontaneous and varied based on their personal experiences. Analysis revealed that their responses clustered around six attributes of health care providers' professional practice. These attributes facilitated SDM and enhanced parents' confidence and ability to care for their children. In Table 4, we present these attributes with definitions derived from parents' comments across the three time intervals and illustrative quotations. 
Table 4. Attributes of health care practitioners' professional practice that facilitated shared decision making

\begin{tabular}{|c|c|c|}
\hline Attributes & Definition $\underline{\text { a }}$ & $\begin{array}{l}\text { Cases, }, \underline{\mathbf{b}} \mathbf{N} \\
\text { (\% of } 48)\end{array}$ \\
\hline 1. Accessible & $\begin{array}{l}\text { Are continuously } \\
\text { available }\end{array}$ & $19(40)$ \\
\hline $\begin{array}{l}2 . \\
\text { Approachable }\end{array}$ & $\begin{array}{l}\text { Welcome parents' } \\
\text { questions without } \\
\text { judgment }\end{array}$ & $13(27)$ \\
\hline 3. Dependable & $\begin{array}{l}\text { Do what is promised and } \\
\text { expected }\end{array}$ & $14(29)$ \\
\hline $\begin{array}{l}4 . \\
\text { Knowledgeable }\end{array}$ & $\begin{array}{l}\text { Expertise is present and } \\
\text { readily shared }\end{array}$ & $19(40)$ \\
\hline 5. Supportive & $\begin{array}{l}\text { Anticipate families' } \\
\text { needs and readily } \\
\text { provide assistance }\end{array}$ & $14(29)$ \\
\hline 6. Transparent & $\begin{array}{l}\text { Disclose all information } \\
\text { and acknowledge } \\
\text { limitations }\end{array}$ & $13(27)$ \\
\hline
\end{tabular}
"They're always available to me; I can call any time and they answer my questions; we know they're there if we need them"
"The transplant team is easy to talk to; I feel like I can ask any question; they involve us without being condescending"

"Everybody is doing everything that they can to help us; they're all doing what they're supposed to be doing"

"They're just incredibly smart, gifted people who are very good at keeping us informed and educated"

"They even call to check in on us regularly; they've really helped us get through everything"

"They've been very good about letting us know what could happen; unfortunately for us, it seems that whatever could happen, did happen, but at least I was prepared"

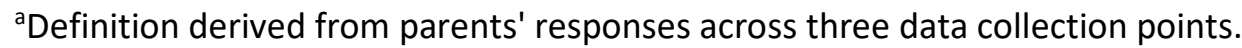

${ }^{\mathrm{b}}$ Number of parents who identified the attribute at the 3-week interview.

Parents appreciated that the transplant team was accessible for questions or concerns 24 hours a day, 7 days a week. Parents also valued a transplant team that was approachable in that they felt comfortable asking questions and were acknowledged as experts on their children. Being dependable was an important attribute because parents felt the transplant team could be counted on to do both what they should and what they promised. A knowledgeable transplant team that was willing to share this knowledge was another essential behavior for parents. Providers were supportive by readily offering help without parents having to request assistance and by routinely calling parents to check in. Transplant team members were described as transparent, highlighting the fact that parents wanted to be kept informed of monitoring efforts with regard to laboratory and other diagnostic tests. Parents wanted to hear the truth and valued knowing about potential adversity or problems. Furthermore, parents expected humility from providers and acknowledgment that they did not have all of the answers.

\section{Discussion}

This study is the first to describe the perspectives of parents of children who received an SOT on their participation in SDM. Our analysis revealed three themes: (a) parents expect to participate in SDM; (b) parents seek out information to participate in SDM; and (c) providers' attributes facilitate SDM. The themes together highlight the duality of SDM - the parent involvement or engagement and the provider contribution through attributes that encourage parent engagement. As an essential part of the patient-provider relationship, SDM enhances patient-centered care by supporting parent/patient involvement in managing the chronic illness. SDM enhances the patient experience, improving quality of patient care, and supporting cost containment (Robert Wood Johnson Foundation, 2013). 
As an essential part of the patient-provider relationship, SDM enhances patient-centered care by supporting parent/patient involvement in managing the chronic illness.

Parents expected to participate in SDM, and overtly discussing SDM is one way to increase patient activation to participate in SDM. By openly discussing SDM, providers can include parents and empower them to recognize that their input is welcome. Although parents expect and prefer to share in decision making, they may not always feel that their providers welcome their participation. Inviting parents to be active participants in their children's care may help even the informed but somewhat passive parents to have increased involvement in SDM.

Parents in this study appeared to genuinely rely on the transplant team to care for their children. Through the SDM process, parents expressed that they perceived they were the final decision makers. Even parents with lower levels of SDM who reported that "we just do what the team tells us" still ultimately made that decision to follow the recommended plan. Given the complexity of the transplantation process for parents to understand, it is important to foster all opportunities to explore fears and concerns (Shellmer et al., 2014). SDM is not about providers "letting" parents be involved, but rather about providers recognizing that parents can be effectively engaged.

The second theme identified was that parents seek out information in order to participate in SDM. Parents came prepared for their health care encounters with information from other sources such as other parents, the Internet, and a variety of specialty and primary health care providers. Conflicting information from what parents read or were told compared with information from the health care team was sometimes a challenge. However, parents viewed the transplant team as the source for the most accurate and trustworthy information to inform their decision making. Thus providers should expect and support this seeking out of information from a variety of sources as a normal part of parents' preparation for SDM. Previous research has reported that parents of transplant recipients have difficulty managing the complex care regimen (Lerret et al., 2015; Lerret \& Weiss, 2011), which may result in posttransplant complications. This exchange of information between the team and parents and children is crucial to decision making to develop a mutually agreed upon treatment plan.

The third theme identified from the transcripts was that professional provider attributes facilitate SDM. Health care team members who were knowledgeable, transparent, approachable, accessible, dependable, and supportive fostered parents' participation in SDM. This finding suggests that parents who practice SDM with health care providers will feel respected and included in treatment decisions and confident that the circumstances, preferences, beliefs, and needs of themselves and their children are acknowledged (Fiks et al., 2010; IOM, 2015). Parent and health care provider discussions of expectations for decision making and care after hospital discharge may improve the experience for families of children who have received a transplant. Parents' understanding inspires trust, confidence, and satisfaction with the transplant team and the overall transplant experience.

Health care team members who were knowledgeable, transparent, approachable, accessible, dependable, and supportive fostered parents' participation in SDM.

This study has some limitations. One limitation is that only one parent was interviewed, and thus the entire family experience was not captured, including that of dual-parent homes. The interview consisted of four questions and was completed over the phone, which may have limited participants' responses. Additionally, homogeneity of the participants was encountered in that parents were largely satisfied with their children's care and all of the children survived their transplants. Interviews with families who had less positive experiences or 
different outcomes may have provided different perspectives on SDM. The participants were mostly white, female, and married, which limits generalizability to other family structures and members. Parents who did not speak English were excluded from the study. Future research with immigrant families from countries where solely physicians make decisions may provide further insight into how to best engage families in SDM.

A strength of this study is the sample size for conducting qualitative exploration and conclusion. Although the sample size was large for qualitative analysis, the structure of the interview that involved direct questioning sometimes resulted in short responses. Probing was used to increase the depths of the responses. Furthermore, parents were enrolled at five major pediatric hospitals across the United States, which increases the transferability of these results.

\section{Conclusion}

The transplant experience is challenging for families, but parents who participate in SDM benefit from the relationship with the transplant team. Health care providers can intentionally use the six key attributes to engage parents in SDM. Future studies are needed to assess the relationship of SDM, patient activation, and health outcomes in this growing population of children with transplants. Although not directly generalizable, the results from parents of children who received a transplant provide a framework to consider enhancing SDM in other chronic illness populations.

We thank Dr. Marianne Weiss for her support and thoughtful review of the manuscript. We also thank the following persons who demonstrated dedication to this work through participant enrollment and data collection: Gail Stendahl, Shelley Chapman, Jerome Menendez, Laurel Williams, Michelle Nadler, Katie Neighbors, and Katie Amsden.

\section{References}

Aldridge, 2008 M.D. Aldridge How do families adjust to having a child with chronic kidney failure? Nephrology Nursing, 35 (2) (2008), pp. 157-162

Barr et al., 2014 P.J. Barr, R. Thompson, T. Walsh, S.W. Grande, E.M. Ozanne, G. Elwyn The psychometric properties of CollaboRATE: A fast and frugal patient-reported measure of the shared decision-making process Journal of Medical Internet Research, 16 (1) (2014), p. e2

Charles et al., 1997 C. Charles, A. Gafni, T. Whelan Shared decision-making in the medical encounter: What does it mean? (Or it takes at least two to tango) Social Science and Medicine, 44 (5) (1997), pp. 681-692

Committee on Hospital Care and Institute for Patient and Family Centered Care, 2012 Committee on Hospital Care and Institute for Patient and Family Centered Care Patient and family centered care and the pediatrician's role Pediatrics, 129 (2) (2012), pp. 394-404

Coyne et al., 2013 I. Coyne, D.P. O'Mathuna, F. Gibson, L. Shields, G. Sheaf Interventions for promoting participation in shared decision-making for children with cancer The Cochrane Database of Systematic Reviews, 6 (2013), p. CD008970

Fiks et al., 2010 A.G. Fiks, A.R. Localio, E.A. Alessandrini, D.A. Asch, J.P. Guevara Shared decision-making in pediatrics: A national perspective Pediatrics, 126 (2) (2010), pp. 306-314 
Fiks et al., 2011 A.G. Fiks, C.C. Hughes, A. Gafen, J.P. Guevara, F.K. Barg Contrasting parents' and pediatricians' perspectives on shared decision-making in ADHD Pediatrics, 127 (1) (2011), pp. e188-e196

Hibbard and Greene, 2013 J.H. Hibbard, J. Greene What the evidence shows about patient activation: Better health outcomes and care experiences; fewer data on costs Health Affairs (Milwood), 32 (2) (2013), pp. 207-214

Informed Medical Decisions Foundation, 2015 Informed Medical Decisions Foundation Affordable Care Act (2015) Retrieved from http://www.informedmedicaldecisions.org/shared-decision-makingpolicy/federal-legislation/affordable-care-act/

Institute of Medicine, 2001 Institute of Medicine Crossing the quality chasm: A new health system for the 21st century National Academies Press, Washington, DC (2001)

Institute of Medicine, 2015 Institute of Medicine Report brief: Vital signs core metrics for health and health care progress (2015) Retrieved from http://www.iom.edu/Reports/2015/Vital-Signs-Core-Metrics.aspx

Jerofke et al., 2014 T. Jerofke, M.E. Weiss, O. Yakusheva Patient perceptions of patient-empowering nurse behaviors, patient activation and functional health status in postsurgical patients with life-threatening long-term illnesses Journal of Advanced Nursing, 70 (6) (2014), pp. 1310-1322

Kavanaugh et al., 2005 K. Kavanaugh, T. Savage, S. Kilpatrick, R. Kimura, P. Hershberger Life support decisions for extremely premature infants: Report of a pilot study Journal of Pediatric Nursing, 20 (5) (2005), pp. 347-359

Lerret and Weiss, 2011 S.M. Lerret, M.E. Weiss Parents of pediatric solid organ transplant recipients and the transition from hospital to home following solid organ transplant Pediatric Transplantation, 15 (2011), pp. 606-616

Lerret et al., 2015 S.M. Lerret, M.E. Weiss, G.L. Stendahl, S. Chapman, J. Menendez, L. Williams, et al., P. Simpson Pediatric solid organ transplant recipients: Transition to home and chronic illness care Pediatric Transplantation, 19 (2015), pp. 118-129

Pentz et al., 2012 R. Pentz, W. Pelletier, M. Alderfer, K. Stegenga, D. Fairclough, P. Hinds Shared decision-making in pediatric allogeneic blood and marrow transplantation: What if there is no decision to make? Oncologist, 17 (6) (2012), pp. 881-885

Robert Wood Johnson Foundation, 2013 Robert Wood Johnson Foundation Health policy brief: Patient engagement Health Affairs, 34 (6) (2013)

Shellmer et al., 2014 D. Shellmer, C. Brosig, J. Wray The start of the transplant journey: Referral for pediatric solid organ transplantation Pediatric Transplantation, 18 (2) (2014), pp. 125-133

\section{Vitae}

Stacee M. Lerret, Assistant Professor, Division of Pediatric Gastroenterology and Transplant Surgery, Medical College of Wisconsin, Milwaukee, WI.

Kristin A. Haglund, Associate Professor, Marquette University, College of Nursing, Milwaukee, WI. 
Norah L. Johnson, Assistant Professor, Marquette University, College of Nursing, Milwaukee, WI.

Supported by a grant from Children's Research Institute Pilot Innovative Research Award and by the National Center for Research Resources and the National Center for Advancing Translational Sciences, National Institutes of Health, grant $\underline{8 \mathrm{UL} 1 T R 000055}$.

Conflicts of interest: None to report. 